\title{
Magnitude and Associated Factors of Suicidal Ideation Among Cancer Patients at Ayder Comprehensive Specialized Hospital, Mekelle, Ethiopia, 2019: Cross-sectional Study
}

\author{
Haftamu Mamo Hagezom (D) \\ Tadele Amare (iD ${ }^{2}$ \\ Getahun Hibdye ${ }^{3}$ \\ Wubit Demeke ${ }^{3}$ \\ 'Department of Psychiatry, Adigrat \\ University College of Medicine and \\ Health Sciences, Adigrat, Ethiopia; \\ ${ }^{2}$ Department of Psychiatry, University of \\ Gondar College of Medicine and Health \\ Sciences, Gondar, Ethiopia; ${ }^{3}$ Department \\ of Psychiatry, Amanuel Mental Specialized \\ Hospital, Addis Ababa, Ethiopia
}

\begin{abstract}
Background: Suicide is a worldwide public health issue and considered as a psychiatric emergency. The majority of all completed suicides occur in low- and middle-income countries. A diagnosis of cancer has been associated with an increased risk of suicidal ideation and suicide is one of the leading causes of non-cancer-related mortality among cancer patients in recent years. Suicidal ideation is four times higher in cancer patients than in the general population. There is limited evidence on suicidal ideation on patients diagnosed with cancer in Ethiopia as well as in African countries.
\end{abstract}

Objective: To assess the magnitude and associated factors of suicide ideation among cancer patients at Ayder Comprehensive Specialized Hospital, Mekelle, Ethiopia, 2019.

Methods: An institution-based cross-sectional study was conducted from May 1 to 30, 2019. Systematic random sampling technique was used and a total of 410 of cancer patients participated in the study. Data were collected using the Suicide Manual of Composite International Diagnostic Interview (CIDI) questionnaire. Data were coded, entered into EpiData manager version 4.4 and analyzed using SPSS version 20. Descriptive, analytical statistical procedures, bivariable, multivariable logistic regression with odds ratio, $95 \%$ confidence interval were employed. The statistical significance was declared at $P$-value $<0.05$.

Results: The finding of the present study on magnitude of suicidal ideation among cancer patients were $28.5 \%$ with $95 \% \mathrm{CI}$ : $24.1-33.2$, respectively. In multivariable logistic regression analysis being female advanced stage, perceived stigma and anxiety was significantly associated with suicidal ideation.

Conclusion and Recommendation: The magnitude of suicidal ideation among cancer patients was higher than in the general population. It also reported that, advanced stage, perceived stigma, anxiety and being female were factors significantly associated with suicidal ideation. This study gives us clues that cancer patients are prone to suicide ideation. Therefore, cancer patients need special attention to reduce these problems.

Keywords: suicide ideation, suicide, cancer, Ethiopia

\section{Introduction}

Suicide is a Latin word which means "self-murderer". It is a fatal act that represents a person's wish, to plan to die and finally acts on it. ${ }^{1}$ Suicide is a serious problem it takes away one's life suddenly and it is also a global public health issue and about 800,000 suicides were documented worldwide, which is one person every 40 seconds. $^{2}$ Globally
Correspondence: Haftamu Mamo Hagezom

Department of Psychiatry, Adigrat University College of Medicine and Health Sciences, PO Box: 50, Adigrat, Ethiopia Tel +25l 0988494909

Email haftish6108@gmail.com 
$78 \%$ of all completed suicides occur in low- and middleincome countries in 2015 and the estimated global burden of suicide is around $1.4 \%{ }^{3}$ It is estimated to contribute more than $2.4 \%$ of the global burden of disease by the year $2020 .^{4}$ Study shows that national cost of suicide in the United States in 2013 was around 58.4 billion dollars. 5,6

The burden of suicide in African regions ranges from 0.5 to $1.9 \%$ excluding the Eastern Mediterranean region/ the Arabic countries. ${ }^{2}$ Another study shows that suicide death was estimated to be 34,000 per year in the majority of sub-Saharan African countries and reported that the suicide rate was three times higher in men than in women. ${ }^{7}$ In Ethiopia completed suicide was 7.7/100,000/years. ${ }^{8}$

Cancer is a devastating medical illness both physically and mentally. ${ }^{9}$ Noncommunicable diseases (NCDs) are now responsible for the majority of global deaths and cancer is expected to rank as the leading cause of death and the single most important barrier to increasing life expectancy in every country of the world in the twentyfirst century. ${ }^{1}$ According to estimates from the World Health Organization (WHO) in 2015, cancer is the second leading cause of death before the age of 70 years in 91 of 172 countries, and it ranks fourth in an additional 22 countries. ${ }^{10}$ In Ethiopia, cancer accounts for about 5.8\% of total national mortality. Although population-based data do not exist in the country except for Addis Ababa, it is estimated that the annual incidence and mortality rate is around 60,960 and over 44,000, respectively in cancer patients. ${ }^{11}$

Suicidal ideation that occurs among cancer patients is higher, which is approximately twice that of the general population. ${ }^{12,13}$ Being diagnosed with cancer has been associated with an increased risk of suicidal ideation and suicide is one of the leading causes of non-cancer-related mortality among cancer patients In recent years. ${ }^{14}$

A literature review done in the UK reported that percentages of suicidal ideation in cancer patients ranged from 0.8 to $71.4 \%$, which was higher compared to a reported prevalence of suicidal ideation in the general population. ${ }^{15}$ Another study in England in 2017 showed that 2491 out of 4,722,099 cancer patients died by suicide. ${ }^{16}$ Patients with gastric cancer have four times higher risk of suicide compared with the general population and the suicide risk is highest within the first three months after diagnosis. A population-based follow-up study was conducted in Japan to assess the risk of suicide among patients with cancer. From 65,535 patients with cancer 65 died by suicide. ${ }^{17}$
In a total of $1,005,825$ patients who died within the first year after their cancer diagnosis, $0.16 \%$ died by suicide in United Nations. ${ }^{18}$ Most patients who committed suicide were male and 65 to 84 years old when they were diagnosed with cancer. ${ }^{18}$ Another study in UN reported that 13,311 out of 8,651,569 cancer patients committed suicide and the rate of suicide was $28.58 / 100,000$-person years. ${ }^{19}$ One thousand four hundred and thirty-two out of 1.3 million cancer patients died by suicide in Canada. ${ }^{20}$ Five hundred and three out of 9841 suicides were among cancer patients in Tokyo and suicide was higher among the elderly. ${ }^{21}$ Suicidal ideations were relatively higher among cancer patients with pain than those without pain. ${ }^{22}$

Although suicidality is common in developing and developed countries with chronic medical problems, little attention is paid to it outside mental health or psychiatric settings. ${ }^{5}$ In Ethiopia suicide ideation was a higher magnitude among patients with severe mental illness and other chronic illness. But little attention is paid to identify suicidal ideation in cancer patients, which is a common chronic problem. Therefore, the current study was conducted to assess prevalence and associated factors of suicidal ideation among patients with cancer to support integration of the mental health service with cancer management.

\section{Methods}

\section{Study Design, Setting and Period}

An institution-based cross-sectional study was done at Ayder Comprehensive Specialized Hospital, Mekelle which is $763 \mathrm{~km}$ away from Addis Ababa, the capital of Ethiopia. It is the only referral center for cancer in Tigray Regional State. All adult cancer cases $\geq 18$ years' who were attending the ACSH oncology clinic during the data collection period were included in the study.

\section{Sample Size Determination and Sampling Technique}

Samples size was calculated by using single population formula,

$$
n=\frac{\left(Z \frac{\alpha}{2}\right)^{2} p(1-p)}{d^{2}}
$$

Where; $\mathrm{n}=$ sample size

$\mathrm{Z} \frac{\propto}{2}=$ significance level at $\propto=0.05$ 
$\mathrm{P}=$ the prevalence of suicidal ideation and attempt among cancer patients is unknown in our country; hence, $\mathrm{P}=50 \%(0.5)$ will be used.

$\mathrm{d}=$ absolute precision or tolerable margin of error $=0.05$ Therefore,

$$
n=\frac{(1.96)^{2} 0.5(1-0.5)}{0.05^{2}}=384
$$

Considering the sample size $10 \%$ of nonrespondent rate, the size was $384+39=423$. Systematic random sampling technique was used to select study population at Ayder Comprehensive Specialized Hospital during the study period. The first study subject was selected by lottery method. Thereafter, participants were selected at two-patient intervals from the first study subject.

\section{Operational Definitions}

\section{Suicidal Ideation}

If the respondent answers to the question "have you seriously thought about committing suicide with in the last 12 month" and answers yes, the respondent has suicidal ideation according to suicidality module of CIDI. ${ }^{23}$

\section{Social Support}

According to the Oslo-3 social support scale which ranges from 3-14, those respondents who scored 3-8 are considered as having poor social support, score 9-11 considered as having moderate social support and score 12-14 considered as having strong social support. ${ }^{24}$

\section{Depression}

A score of $\geq 8$ in HADS-D indicates presence of depression. ${ }^{25}$

\section{Anxiety}

A score of $\geq 8$ in HADS-A indicates presence of anxiety. ${ }^{25}$

\section{Substance Use}

Current use: using at least one specific substance for nonmedical purpose within the last three months (alcohol, khat, tobacco, others).

Ever use of substance: using at least one of any specific substance for nonmedical purpose at least once in lifetime (alcohol, khat, tobacco, others). ${ }^{26}$

Pain: pain was measured by verbal rating scale (rated as $0=$ no pain, $1=$ mild, $2=$ moderate, $3=$ severe) commonly practiced and recommended in the Ethiopian context. ${ }^{27,28}$

Perceived stigma: based on Jacoby perceived stigma scale: a score of 1 and above indicate the patient is stigmatized. ${ }^{29}$

\section{Data Collection Tools and Procedure}

The data was collected using a structured interview questionnaire. Both chart review and structured interview was used to collect information from the study subjects. Data regarding stages of cancer and type of cancer were filled in from patient's record. Suicidal ideation was assessed using suicidality module of World Mental Health (WMH) survey initiative version 3.0 of the WHO Composite International Diagnostic Interview (CIDI), which is validated in Ethiopia. Social support was assessed using the Oslo social support rating scale, stigma was assessed by Jacoby Perceived Stigma Scale and HADS was used to assess depression and anxiety. Closed and openended questions were used to gather information regarding substance use and sociodemographic characteristics.

\section{Data Quality Assurance}

Three BSc psychiatry and one BSc nurses were data collectors and one MSc in adult health nursing was supervisor. Training for data collectors was given on how to collect data and data collection methods and tools were discussed with the data collectors. Questionnaires were pretested on 5\% (22) of the sample size at ACSH one week before the actual data collection started and it was not included in the main study. The internal consistency of the questionnaires was determined by Cronbach's alpha reliability test and the Cronbach's alpha of the questionnaires was as follows, for suicidal ideation tool $\alpha=0.77$, HADS-A $\alpha=0.824$, HADS-D $\alpha=0.71$, Jacoby 3 scale stigma $\alpha=0.86$, Oslo social support $\alpha=0.82$. Data collectors were supervised regularly by the supervisor and principal investigator to ensure that all necessary data were properly collected each day during data collection.

\section{Data Processing and Analysis}

First the data were checked for completeness and consistency, and then coded. The coded data were entered into EpiData manager version 4.4 and exported to Statistical Package for Social Science (SPSS) version 20 for cleaning and analysis. Simple descriptive results were presented using tables, graphs, and charts. Binary logistic regression was fitted with the data and bivariable and multivariable logistic regression were used. Enter method was used for selection of significant predictors in the multivariable logistic regression analysis. A coefficient was reported as crude and adjusted OR relative to the reference category. Hosmer-Lemeshow goodness of fit model was checked and in multivariable logistic regression analysis $P$-values less than 0.05 were considered statistically significant. 


\section{Ethical Consideration}

Ethical clearance was obtained from institution review board (IRB) of the University of Gondar and Ethical committee of AMSH. A formal letter of permission was obtained from AMSH and ACSH. This research was conducted in accordance with the Declaration of Helsinki. Data were collected after obtaining consent from each participant. Competed questionnaire and computer data were kept confidential. The purpose and importance of the study was explained to study participants and they were informed of the right to withdraw at any time during the study period. Participants were recruited after signing the written informed consent. Personal identification such as name was not reported to maintain the privacy and confidentiality of participants. Participants in the study who were highly suicidal were linked to a psychiatric unit for further assessment and management.

\section{Results}

\section{Sociodemographic Characteristics of}

\section{Respondents}

A total of 423 cancer patients were expected to participate on the study but 410 cancer patients agreed to participate in the study and response rate was $97.0 \%$. From the total participants $51 \%$ were female and $49 \%$ were male. Majority of the participant $(82.9 \%)$ were orthodox by religion and, $75.4 \%$ of the participants were married. A large number of the participants $56.6 \%$ were unemployed and the mean age of the participants was 46.7 and with $\mathrm{SD}=12.28$. (See Table 1)

\section{Clinical Characteristics of Respondents}

The prevalent cancer type was colorectal $21 \%$, followed by breast and blood $17.1 \%$ and $12.9 \%$, respectively. Half of the participants had an advanced stage of cancer and the proportion of anxiety and depression among cancer patients wase $114(27.8 \%)$ and $166(40.5 \%)$, respectively. Out of the total participants $74.6 \%$ of them had pain and the severity of pain was $11.1 \%$ and $88.9 \%$ mild, moderate/ severe, respectively. The mean and SD of duration illness of cancer patients was 12.84 and $\mathrm{SD}= \pm \pm 12.86$ respectively.

\section{Psychosocial Factors of the Respondents} Out of 410 cancer patients $128(31.2 \%)$ had perceived stigma. The majority of the participants had moderate social support. The prevalence of suicidal ideation was 51.6 among those who had perceived stigma.

Table I Sociodemographic Characteristics of the Study Participants Attending the Oncology Clinic in ACSH, Mekelle, Ethiopia, 20I9, $(n=410)$

\begin{tabular}{|l|l|l|}
\hline Variables & Frequency & \\
\hline Sex & 209 & 49 \\
Male & 201 & 51 \\
Female & & \\
\hline Marital status & 309 & 75.4 \\
Married & 44 & 10.7 \\
Single & 57 & 13.9 \\
Divorced/widowed & & \\
\hline Religion & 340 & 82.9 \\
Orthodox & 24 & 5.9 \\
Catholic/protestant & 46 & 11.2 \\
Muslim & & \\
\hline Occupation & 178 & 43.4 \\
Employed & 232 & 56.6 \\
Unemployed & & \\
\hline Educational status & 184 & 44.9 \\
No formal education & 140 & 34.1 \\
Primary/secondary school & 86 & 21 \\
College and above & & \\
\hline
\end{tabular}




\section{Substance Related Factors the Study \\ Participants}

The prevalence of alcohol use was relatively higher than cigarette and khat use among cancer patients it accounts for around $53.7 \%$ lifetime use and from those who use in their lifetime $18.3 \%$ of them uses alcohol currently. (See Table 2.)

\section{Magnitude of Suicidal Ideation Among Cancer Patients}

The magnitude suicidal ideation and attempt in the last 12 months among cancer patients were $28.5 \%$ with $95 \% \mathrm{CI}$ : 24.1-33.2. Suicidal ideation was 32.8\% female, $45.5 \%$, among single and $30.5 \%$ among unemployed cancer patients in the last 12 months. (See Table 3)

\section{Factors Associated with Suicidal Ideation Among Cancer Patients}

Binary logistic regression was done for each factor of suicidal ideation among cancer patients. In bivariable logistic regression analysis, factors like, being female, type of cancer (cervical), advanced stage, having pain, family history of mental illness, depression, anxiety and perceived stigma were fulfilled requirement for multivariable logistic regression analysis at
$P<0.2$ and then exported to multivariable logistic regression analysis. Multivariable logistic regression analysis was done and the model was checked for fitness using the HosmerLemeshow test and the $P$-value was 0.36 .

In multivariable logistic regression no formal education, advanced stage of cancer, anxiety and having perceived stigma were significantly associated at $P$-value $<0.05$. In this study 71\% (AOR: 0.29 , 95\%CI: $0.14-0.63$ ) of cancer patients with no formal education were less likely to have suicidal ideation than those whose educational status was college and above. The odds of suicidal ideation was about two (AOR: 2.15, 95\%CI: 1.13-4.07) times higher among patients with an advanced stage of cancer than those with an early stage of cancer (See Table 4.)

Cancer patients with anxiety were almost twice as (AOR, $2.28,95 \% \mathrm{CI}, 1.21,4.31)$ likely to have suicidal ideation compared with those who had no anxiety. The odds of having suicidal ideation was around six (AOR: 6.15, 95\%CI: 3.4311.04) times higher among cancer patients with perceived stigma compared to no perceived stigma. (See Table 4.)

\section{Discussion}

In this study magnitude of suicidal ideation in the last 12 months among cancer outpatients was $28.5 \%(95 \% \mathrm{CI}$ :

Table 2 Frequency Distribution of Substance Related Factors of the Participants Attending the Oncology Clinic in ACSH, Mekelle, Ethiopia, 2019, $(n=410)$

\begin{tabular}{|l|l|l|}
\hline Variables & Frequency & Percent (\%) \\
\hline $\begin{array}{l}\text { Ever use of alcohol drinking } \\
\text { Yes }\end{array}$ & 220 & 53.7 \\
No & 190 & 46.3 \\
\hline $\begin{array}{l}\text { Ever use khat chewing } \\
\text { Yes }\end{array}$ & 8 & \\
No & 402 & 2 \\
\hline $\begin{array}{l}\text { Ever use cigarette smoking } \\
\text { Yes }\end{array}$ & 21 & 98 \\
No & 389 & 5.1 \\
\hline $\begin{array}{l}\text { Current use of alcohol drinking } \\
\text { Yes }\end{array}$ & & 94.9 \\
No & 75 & \\
\hline $\begin{array}{l}\text { Current use khat chewing } \\
\text { Yes }\end{array}$ & 335 & 18.3 \\
No & 3 & 81.7 \\
\hline $\begin{array}{l}\text { Current use cigarette smoking } \\
\text { Yes }\end{array}$ & 407 & \\
No & 8 & 9.7 \\
\hline
\end{tabular}


Table 3 Frequency Distribution of Suicidal Ideation Among Participants Attending the Oncology Clinic in ACSH, Mekelle, Ethiopia, 2019, $(n=410)$

\begin{tabular}{|l|l|l|}
\hline Variables & Frequency & Percent (\%) \\
\hline Ever suicidal ideation & & \\
Yes & 123 & 30 \\
No & 287 & 70 \\
\hline Suicidal ideation in 12 months & & \\
Yes & 117 & 28.5 \\
No & 293 & 71.5 \\
\hline Ever plan suicide & & \\
Yes & 22 & 5.4 \\
No & 388 & 94,6 \\
\hline
\end{tabular}

24.1-33.2). This finding was consistent with the studies done in Korea, $24.7 \%$ Colombia $24.5 \%$, and the US, $26 \%{ }^{30-32}$

However, this study had a lower magnitude of suicidal ideation than a study conducted in Portugal which was $35 \%{ }^{33}$ The possible explanation for this discrepancy could be difference in sample size, tool used to assess the suicidal ideation was the Beck Scale for Suicide Ideation and another possible reason might be that the majority of the participants (73\%) were female. It was also lower than study conducted in Japan which was $53.5 \%$ the possible reason could be that this study was conducted on cancer patients with depression; this might lead to suicide. ${ }^{34}$

The present finding of suicidal ideation among cancer patients was higher than a study conducted in Germany which was $5.8 \%{ }^{35}$ The possible reasons could be due to the different study designs in Germany; they used a comparative cohort study and the sampling technique was also different. The other possible reason might be cancer patients in Germany might be satisfied with the service they got since Germany a developed country, they might be using advanced technology to carry out the health care delivery system and they might also get mental health service.

This study was also higher than a study conducted in China which was $15.3 \%$. The possible reason for this discrepancy might be due to the length of study period because it was one months prevalence, but the present study was 12 months prevalence. Another possible reason might be that a large number of the participants $(94.6 \%)$ in that study were married. ${ }^{36}$ A study conducted in Canada showed a lower prevalence of suicidal ideation (4.2\%) than the current study. ${ }^{37}$ The possible explanation might be that in Canada they used a population-based cohort study. Another study conducted in Italy reported lower prevalence of suicidal ideation $(18 \%)$ than this study. ${ }^{38}$ The possible reason for this difference might be due to the integration of oncology with psychiatry service which helps cancer patients to get psychological support and other psychiatric service early. The finding of this study was a higher magnitude of suicidal ideation among cancer patients than studies done in Japan (15\%) and UK $(11 \%) .{ }^{39}$ This might be due to different study design, a population-based cohort study was used in both studies and the tools used to assess suicidal ideation, which were not the same as this study.

Factors associated with suicidal ideation in this study were, being female, no formal education, advanced stage of cancer, perceived stigma, and having anxiety significantly, associated in multivariate logistic regression analysis.

The odds of suicidal ideation was about twice as (AOR: 2.33, 95\%CI: 1.03-5.28) likely in female compared to male cancer patients. This finding was supported by studies conducted in South Korea ${ }^{30}$ and Portugal. ${ }^{33}$ The possible reason might be due to females being less likely to express their ideas and feelings owing to different cultural and religious influences. This might lead them to become depressed and finally they might have suicidal ideation.

Cancer patients with no formal education were $71 \%$ (AOR: $0.29,95 \% \mathrm{CI}: 0.14-0.63$ ) less likely to have suicidal ideation than those with college and above educational status. There is no study that shows no formal education less likely to have suicidal ideation, but the possible 
Table 4 Bivariable and Multivariable Logistic Regression Analysis Showing Factors Associated with Suicidal Ideation Among Cancer Outpatient Attending the Oncology Clinic at ACSH, Mekelle, Ethiopia, 2019, $(n=410)$

\begin{tabular}{|c|c|c|c|c|}
\hline \multirow[t]{2}{*}{ Variables } & \multicolumn{2}{|c|}{ Suicidal Ideation } & \multirow[t]{2}{*}{ COR $(95 \% \mathrm{Cl})$} & \multirow[t]{2}{*}{ AOR (95\% CI) } \\
\hline & Yes (\%) & No (\%) & & \\
\hline \multirow[t]{2}{*}{ Age } & Mean & SD & \multirow[t]{2}{*}{$0.97(0.96-0.99)$} & \multirow[t]{2}{*}{$0.999(0.97-1.03)$} \\
\hline & 46.5 & $\pm \mathbf{I} 2.86$ & & \\
\hline \multicolumn{5}{|l|}{ Sex } \\
\hline Male & 51 & 158 & I & I \\
\hline Female & 66 & 135 & $1.52(0.98-2.33)$ & $2.33(1.03-5.28) *{ }^{\mathrm{a}}$ \\
\hline \multicolumn{5}{|l|}{ Marital status } \\
\hline Married & 82 & 227 & 1 & 1 \\
\hline Single & 20 & 24 & $2.31(1.21,4.40)$ & I. $14(0.40-3.25)$ \\
\hline Divorced & 15 & 42 & $0.99(0.52-1.89)$ & $1.01(0.4 \mathrm{I}-2.48)$ \\
\hline \multicolumn{5}{|l|}{ Educational status } \\
\hline No formal education & 39 & 145 & $0.324(0.19-0.563)$ & $0.29(0.14-0.63)^{* *}, \mathrm{a}$ \\
\hline Secondary school & 39 & 101 & $0.47(0.27-0.82)$ & $0.55(0.26-\mid .21)$ \\
\hline College and above & 39 & 47 & I & I \\
\hline \multicolumn{5}{|l|}{ Stage of cancer } \\
\hline Early & 37 & 142 & I & I \\
\hline Advanced & 77 & 128 & $2.31(1.46-3.65)$ & $2.15(1.13-4.07)^{*}$ \\
\hline Unknown & 3 & 23 & $0.50(0.14-1.76)$ & $0.42(0.08-2.15)$ \\
\hline \multicolumn{5}{|l|}{ Type of cancer } \\
\hline Lung & 13 & 22 & I & I \\
\hline Colorectal & 26 & 60 & $0.72 \mid(0.32-1.65)$ & $0.49(0.15-1.65)$ \\
\hline Breast & 30 & 40 & $1.27(0.55-2.92)$ & $0.58(0.14-2.2)$ \\
\hline Cervical & 10 & 33 & $0.51(0.19-1.37)$ & $0.21(0.05-1.90)$ \\
\hline Prostate & 7 & 26 & $0.47(0.16-1.4)$ & $0.31(0.07-1.35)$ \\
\hline Blood & 12 & 41 & $0.49(0.19-1.27)$ & $0.56(0.17-1.82)$ \\
\hline Lymphoma & 10 & 36 & $0.470(0.176-1.25)$ & $0.639(0.19-2.33)$ \\
\hline Stomach & 9 & 35 & $0.435(0.16-1.19)$ & $0.43(0.11-1.68)$ \\
\hline \multicolumn{5}{|l|}{ Type of treatment } \\
\hline Surgery & 24 & 37 & & I \\
\hline Chemotherapy & 53 & 166 & $1.49(0.27-0.90)$ & $0.48(0.19-1.20)$ \\
\hline Surgery and chemotherapy & 40 & 90 & $0.69(0.36-1.29)$ & $0.40(0.17-0.95)^{*}$ \\
\hline \multicolumn{5}{|l|}{ Perceived stigma } \\
\hline Yes & 66 & 62 & $4.82(3.04-7.64)$ & $6.15(3.43-11.04) * \mathrm{a}^{\mathrm{a}}$ \\
\hline No & 51 & 231 & 1 & 1 \\
\hline \multicolumn{5}{|l|}{ Oslo social support } \\
\hline Poor & 53 & 87 & $3.01(1.66-5.49)$ & $1.95(0.92-4.14)$ \\
\hline Moderate & 45 & 112 & $1.99(1.09-3.63)$ & $2.10(0.95-4.47)$ \\
\hline Strong & 19 & 94 & 1 & 1 \\
\hline \multicolumn{5}{|l|}{ Family history of mental illness } \\
\hline Yes & 12 & 14 & $2.29(1.02-5.10)$ & $1.6(0.58-4.37)$ \\
\hline No & 105 & 279 & I & I \\
\hline \multicolumn{5}{|l|}{ Presence of pain } \\
\hline Yes & 97 & 209 & $1.95(1.13-3.36) \mid$ & $1.70(0.86-3.70)$ \\
\hline No & 20 & 84 & & I \\
\hline
\end{tabular}


Table 4 (Continued).

\begin{tabular}{|c|c|c|c|c|}
\hline \multirow[t]{2}{*}{ Variables } & \multicolumn{2}{|c|}{ Suicidal Ideation } & \multirow[t]{2}{*}{ COR $(95 \% \mathrm{Cl})$} & \multirow[t]{2}{*}{ AOR (95\% CI) } \\
\hline & Yes (\%) & No (\%) & & \\
\hline \multirow[t]{2}{*}{ Age } & Mean & SD & \multirow[t]{2}{*}{$0.97(0.96-0.99)$} & \multirow[t]{2}{*}{$0.999(0.97-1.03)$} \\
\hline & 46.5 & $\pm \mathbf{1 2 . 8 6}$ & & \\
\hline \multicolumn{5}{|l|}{ Anxiety } \\
\hline Yes & 53 & 61 & $3.150(1.99-4.99)$ & $2.28(I .2 I-4.3 I)^{*},^{\mathrm{a}}$ \\
\hline No & 64 & 232 & I & I \\
\hline \multicolumn{5}{|l|}{ Depression } \\
\hline Yes & 70 & 96 & $3.06(1.96-4.76)$ & $1.87(0.94-3.70)$ \\
\hline No & 47 & 197 & I & I \\
\hline \multicolumn{5}{|l|}{ Ever use of alcohol drinking } \\
\hline Yes & 75 & 145 & $1.823(1.17-2.84)$ & $1.25(0.69-2.28)$ \\
\hline No & 42 & 148 & I & I \\
\hline \multicolumn{5}{|l|}{ Ever use cigarette smoking } \\
\hline Yes & 12 & 9 & $3.61(1.48-8.81)$ & $2.50(0.74-8.26)$ \\
\hline No & 105 & 284 & I & I \\
\hline
\end{tabular}

Notes: I, reference. *Variables with $P$-value less than $0.01,{ }^{* *}$ variables with $P$-value less than 0.05 in multivariable logistic regression analysis. ${ }^{a}$ Variables that show significant association in multivariable logistic regression analysis.

Abbreviations: AOR, adjusted odd ratio; COR, crude odd ratio.

explanation for this finding might be due to the strict adherence to religious or personal beliefs that prevents them from suicide, lack of enough information regarding the severity of their illness and the treatment outcome of the participants because little was said regarding cancer in our country by the social media as well as by other responsible bodies like they did with other chronic illnesses such as HIV and TB.

The odds of suicidal ideation was around two (AOR: 2.15, 95\%CI:, 1.13-4.07) times higher among patients with advanced stage of cancer than early stage. This was supported by studies conducted in China and Canada. ${ }^{20,36}$ This could be due to increasing suffering from pain and loss of physical appearance due to anticancer side effects as well as surgery. Another possible reason might be anticancer has depressing effects on the patients and depression might be increase the risk of suicide.

Cancer patients with anxiety were almost twice as (AOR: 2.28, 95\%CI: 1.21-4.31) likely to have suicidal ideation than those who had no anxiety. This was in line with studies done in China, ${ }^{36}$ South Korea, ${ }^{30}$ Turkey, ${ }^{40}$ and Portugal. ${ }^{33}$ The possible reason might be psychiatric disorders are risk factors for suicide and anxiety increases the risk of suicidal ideation by changing the brain chemistry, specifically serotonin, which plays a great role in maintaining mood. ${ }^{1,2}$ Sixty percent of cancer patients who had surgery and chemotherapy (AOR: $0.40,95 \% \mathrm{CI}$ : $0.17-0.95$ ) were less likely to have suicidal ideation. There is no study consistent with this finding but the possible reason could be cancer patients having these types of treatment might feel satisfied and think about getting better soon.

The odd of having suicidal ideation was around six (AOR: 6.15, 95\%CI: 3.43-11.04) times higher among cancer patients with perceived stigma compared to those had no perceived stigma. This finding was in line with studies conducted in Australia ${ }^{41}$ and the UK. ${ }^{42}$ The possible reason for this discrepancy might be due to effects of cancer treatment on physical appearance of the patients. Another possible reason could be the attitude and knowledge of people toward cancer; they might consider it a communicable disease. Different studies show that stigma increases the risk of suicide. ${ }^{43}$

\section{Conclusion}

The magnitude of suicidal ideation among cancer patients was higher than in the general population. It also reported that advanced stage, perceived stigma, anxiety, and being female were factors significantly associated with suicidal ideation. According to this finding cancer patients with 
anxiety and perceived stigma had higher suicidal ideation. This study gives us clues that cancer patients are prone to suicide ideation. Therefore, cancer patients need special attention to reduce these problems.

\section{Abbreviations}

ACSH, Ayder Comprehensive Specialized Hospital; AMSH, Amanuel Mental Specialized Hospital; AOR, Adjusted Odds Ratio; COR, Crude Odds Ratio; SPSS, Statistical Package for Social Sciences.

\section{Data Sharing Statement}

Data used and analyzed during the study can be available from the crosseponding authors if needed.

\section{Consent to Publish}

Not applicable for this section.

\section{Acknowledgment}

We should like to thank to the study participants for being voluntary participants in this study and the institutions that allow us to carry out the study. Authors have no funding to report.

\section{Disclosure}

The authors report no conflicts of interest in this work.

\section{References}

1. Kaplan H. Kaplan and Sadock's synopsis of psychiatry: behavioral sciences/clinical psychiatry. Tijdschr Psychiatr. 2016;58(1):78-79.

2. Bachmann S. Epidemiology of suicide and the psychiatric perspective. Int J Environ Res Public Health. 2018;15(7):1425. doi:10.3390/ ijerph15071425

3. Organization WH. National Suicide Prevention Strategies: Progress, Examples and Indicators; 2018.

4. Organization WH. Preventing Suicide: A Global Imperative. World Health Organization; 2014.

5. Shepard DS, Gurewich D, Lwin AK, Reed GA Jr, Silverman MM. Suicide and suicidal attempts in the United States: costs and policy implications. Suicide LifeThreatening Behav. 2016;46(3):352-362. doi:10.1111/sltb.12225

6. Organization WH. Public Health Action for the Prevention of Suicide: A Framework; 2012.

7. Mars B, Burrows S, Hjelmeland H, Gunnell D. Suicidal behaviour across the African continent: a review of the literature. BMC Public Health. 2014;14:606. doi:10.1186/1471-2458-14-606

8. Fdroemo H. National Mental Health Strategy 2012/13-2015/16. 2012.

9. Kotchen TA. Harrison's Principles of Internal Medicine. Vol. 2. 19th ed. McGraw Hill Education; 2015

10. Bray F, Ferlay J, Soerjomataram I, Siegel RL, Torre LA, Jemal A. Global cancer statistics 2018: GLOBOCAN estimates of incidence and mortality worldwide for 36 cancers in 185 countries. CA Cancer J Clin. 2018;68(6):394-424. doi:10.3322/caac.21492
11. Woldeamanuel YW, Girma B, Teklu AM. Cancer in Ethiopia. Lancet Oncol. 2013;14(4):289-290. doi:10.1016/S1470-2045(12)70399-6

12. Angachi MO. The Psychosocial Aspects Among Adult Cancer Patients Attending Oncology Clinic at Moi Teaching and Referral Hospital, Eldoret. Kenya: University of Nairobi; 2014.

13. Anguiano L, Mayer DK, Piven ML, Rosenstein D. A literature review of suicide in cancer patients. Cancer Nurs. 2012;35(4):E14E26. doi:10.1097/NCC.0b013e31822fc76c

14. Yousaf U, Christensen M-L, Engholm G, Storm H. Suicides among Danish cancer patients 1971-1999. Br J Cancer. 2005;92(6):995. doi:10.1038/sj.bjc.6602424

15. Robson A, Scrutton F, Wilkinson L, MacLeod F. The risk of suicide in cancer patients: a review of the literature. Psycho-oncology. 2010;19(12):1250-1258. doi:10.1002/pon.1717

16. Henson KE, Brock R, Charnock J, Wickramasinghe B, Will O, Pitman A. Risk of suicide after cancer diagnosis in England. JAMA Psychiatry. 2019;76(1):51-60. doi:10.1001/ jamapsychiatry.2018.3181

17. Sugawara A, Kunieda E. Suicide in patients with gastric cancer: a population-based study. Jpn J Clin Oncol. 2016;46(9):850-855. doi:10.1093/jjco/hyw075

18. Saad AM, Gad MM, Al-Husseini MJ, et al. Suicidal death within a year of a cancer diagnosis: a population-based study. Cancer. 2019;125(6):972-979. doi:10.1002/cncr.31876

19. Zaorsky NG, Zhang Y, Tuanquin L, Bluethmann SM, Park HS, Chinchilli VM. Suicide among cancer patients. Nat Commun. 2019;10(1):207. doi:10.1038/s41467-018-08170-1

20. Kendal W. Suicide and cancer: a gender-comparative study. Ann Oncol. 2006;18(2):381-387. doi:10.1093/annonc/mdl385

21. Fujimori M, Hikiji W, Tanifuji T, et al. Characteristics of cancer patients who died by suicide in the Tokyo metropolitan area. Jpn J Clin Oncol. 2017;47(5):458-462. doi:10.1093/jjco/hyx003

22. Nuhu F, Odejide O, Adebayo K, Yusuf A. Psychological and physical effects of pain on cancer patients in Ibadan, Nigeria. Afr j Psychiatry. 2009;12(1):64-70. doi:10.4314/ajpsy.v12i1.30281

23. Kessler RC, Üstün TB. The world mental health (WMH) survey initiative version of the world health organization (WHO) composite international diagnostic interview (CIDI). Int $J$ Methods Psychiatr Res. 2004;13(2):93-121. doi:10.1002/mpr.168

24. Dalgard OS, Dowrick C, Lehtinen V, et al. Negative life events, social support and gender difference in depression. Soc Psychiatry Psychiatr Epidemiol. 2006;41(6):444-451. doi:10.1007/s00127-0060051-5

25. Reda AA. Reliability and validity of the Ethiopian version of the hospital anxiety and depression scale (HADS) in HIV infected patients. PLoS One. 2011;6(1):e16049. doi:10.1371/journal. pone. 0016049

26. Henry-Edwards S, Humeniuk R, Ali R, Poznyak V, Monteiro M. The Alcohol, Smoking and Substance Involvement Screening Test (ASSIST): Guidelines for Use in Primary Care (Draft Version 1.1 For Field Testing). Geneva: World Health Organization; 2003.

27. Brunelli C, Zecca E, Martini C, et al. Comparison of numerical and verbal rating scales to measure pain exacerbations in patients with chronic cancer pain. Health Qual Life Outcomes. 2010;8(1):42. doi:10.1186/1477-7525-8-42

28. Hjermstad MJ, Fayers PM, Haugen DF, et al. Studies comparing numerical rating scales, verbal rating scales, and visual analogue scales for assessment of pain intensity in adults: a systematic literature review. J Pain Symptom Manage. 2011;41(6):1073-1093. doi:10.1016/j.jpainsymman.2010.08.016

29. Jacoby A. Felt versus enacted stigma: a concept revisited: evidence from a study of people with epilepsy in remission. Soc Sci Med. 1994;38(2):269-274. doi:10.1016/0277-9536(94)90396-4

30. Park SA, Chung SH, Lee Y. Factors associated with suicide risk in advanced cancer patients: a cross-sectional study. Asian Pac j Cancer Prev. 2016;17(11):4831. doi:10.22034/APJCP.2016.17.11.4831 
31. Kim JM, Jang JE, Stewart R, et al. Determinants of suicidal ideation in patients with breast cancer. Psycho-oncology. 2013;22(12):28482856.

32. Leal-Hernández DA, Sandoval L, Palacios-Espinosa X, Tovar Cuevas J. Proposed scales for measuring suicidal ideation in adult cancer patients. Open J Med Psychol. 2014;3:79-86. doi:10.4236/ ojmp. 2014.31010

33. Madeira N, Albuquerque E, Santos T, Mendes A, Roque M. Death ideation in cancer patients: contributing factors. J Psychosoc Oncol. 2011;29(6):636-642. doi:10.1080/07347332.2011.615381

34. Akechi T, Okamura H, Kugaya A, et al. Suicidal ideation in cancer patients with major depression. Jpn J Clin Oncol. 2000;30(5):221224. doi:10.1093/jjco/hyd057

35. Vehling S, Kissane DW, Lo C, et al. The association of demoralization with mental disorders and suicidal ideation in patients with cancer. Cancer. 2017;123(17):3394-3401. doi:10.1002/cncr.30749

36. Zhong B-L, Li S-H, Lv S-Y, et al. Suicidal ideation among Chinese cancer inpatients of general hospitals: prevalence and correlates. Oncotarget. 2017;8(15):25141. doi:10.18632/oncotarget.15350

37. Rasic DT, Belik SL, Bolton JM, Chochinov HM, Sareen J. Cancer, mental disorders, suicidal ideation and attempts in a large community sample. Psycho Oncol. 2008;17(7):660-667. doi:10.1002/pon.1292
38. Costantini A, Pompili M, Innamorati M, et al. Psychiatric pathology and suicide risk in patients with cancer. J Psychosoc Oncol. 2014;32 (4):383-395. doi:10.1080/07347332.2014.917136

39. Kim JM, Jang JE, Stewart R, et al. Determinants of suicidal ideation in patients with breast cancer. Psycho-Oncology. 2013;22(12):28482856.

40. Mcb Ş, Kaya V, Şen CA, Kaya K. Association between suicidal ideation and behavior, and depression, anxiety, and perceived social support in cancer patients. Med Sci Monitor. 2014;20:329. doi:10.12659/MSM.889989

41. Chapple A, Ziebland S, McPherson A. Stigma, shame, and blame experienced by patients with lung cancer: qualitative study. $B M J$. 2004;328(7454):1470. doi:10.1136/bmj.38111.639734.7C

42. Else-Quest NM, LoConte NK, Schiller JH, Hyde JS. Perceived stigma, self-blame, and adjustment among lung, breast and prostate cancer patients. Psychol Health. 2009;24(8):949-964. doi:10.1080/ 08870440802074664

43. Carpiniello B, Pinna F. The reciprocal relationship between suicidality and stigma. 2017;8:35.

\section{Publish your work in this journal}

Cancer Management and Research is an international, peer-reviewed open access journal focusing on cancer research and the optimal use of preventative and integrated treatment interventions to achieve improved outcomes, enhanced survival and quality of life for the cancer patient.
The manuscript management system is completely online and includes a very quick and fair peer-review system, which is all easy to use. Visit http://www.dovepress.com/testimonials.php to read real quotes from published authors. 